\title{
Social Anxiety Disorder
}

National Cancer Institute

\section{Source}

National Cancer Institute. Social Anxiety Disorder. NCI Thesaurus. Code C34927.

An anxiety disorder characterized by an intense, irrational fear of one or more social or performance situations in which the individual believes that he or she will be scrutinized by others. Exposure to social situations immediately provokes an anxiety response. In adults, the social phobia is recognized as excessive or unreasonable. 